\title{
TAKING RISKS-ADAPTING THE AALBORG PROBLEM BASED LEARNING MODEL IN A NEW FIRST YEAR ENGINEERING DESIGN CURRICULUM
}

\author{
Jeff BARRIE and Thea MORGAN \\ School of Civil, Aerospace and Mechanical Engineering, University of Bristol
}

\begin{abstract}
An introduction to design for first year engineering students contains many facets. Students are expected to learn and demonstrate their knowledge of design processes, drawing, and computer-aided-design. In a new interdisciplinary design unit, students were given an ongoing individual design project which assessed their understanding of design, as well as competencies and skills in using their drawing, computer-aided design (CAD) and programming skills - they were also introduced to design through a design challenge that enhanced their individual and collective learning run in partnership with Engineers without Borders. This paper discusses the challenges of not only delivering such an ambitious model to first year engineering students from multiple disciplines-but the online and face-to-face teaching delivery that had to be implemented under Covid-19 restrictions. This paper documents a challenging year for all design educators, with significant uncertainty and rapidly changing circumstances. The conclusions of the paper are that Problem-Based Learning alone may not be suitable for engineering teaching in the first year of study, and with students who are getting to grips with blended learning and self-directed study. A hybrid model of problem and project-based learning may be more adaptable to different learning styles. If Problem-Based Learning is solely to be used it should place more emphasis on team work rather than individual competencies. Further work is to be explored in hybrid or hyflex online and in-class teaching to make the most out of activities linked with Project and Problem-Based Learning.
\end{abstract}

Keywords: Multi-disciplinary, Problem-Based Learning, Project-Based Learning, hybrid delivery, inter-disciplinary, engineering systems, Covid-19

\section{INTRODUCTION}

The impact of Covid-19 has proved to be a significant and ongoing challenge for Higher Education providers in the UK in 2020. There was a rapid transition from face-to-face teaching to online and blended delivery, with significant restrictions on the capacity of teaching spaces and safety measures in place. Some problem focused subjects such as Maths and Engineering Science subjects, typically delivered via lectures and problem classes, seemed to have adapted well to this transition, however, the move to blended learning has proved challenging and difficult for practical aspects of engineering and design education-in particular, studio-based design classes, labs, and workshop-based activities. For many design educators, a new approach was required - and this was the case for a 20-credit first year Design \& Computing unit; originally delivered to Civil Engineering students the previous year to give them a foundation on sketching, design process and computer-aided design (CAD), as well as basic mathematical modelling and programming skills. As a conjoined unit, which focused on both design and computing as well as for the purposes and scope of the paper, the design element of the conjoined unit will be the primary focus of this study. The unit intended learning outcomes remained the same for 2020 delivery, however there was a significant reduction in face-to-face synchronous teaching, with many aspects of the unit delivered online. The unit was also not only delivered to Civil Engineering students, but to the entire first year of the School of Engineering-including Engineering Design, Mechanical and Aerospace Engineering students, effectively growing the cohort size fivefold to almost 
600 students. This required a broader approach to teaching design, which was not discipline specific. Another challenge was that the unit had many aspects that had to be delivered via a combination of online asynchronous (self-study, pre-recorded lectures, reading and activities) and online synchronous (online meetings, webinars, and workshops) as well as live synchronous (labs and studio-based work) sessions; of which the latter was restricted in limited sessions per week with significant capacity restrictions in the teaching space. This was also coupled with a demand to significantly reduce assessments across each engineering programme.

\section{PROBLEM BASED LEARNING AALBORG MODEL AND INTERDISCIPLINARY APPROACH}

With significant changes to the scope and delivery of the unit, the teaching material had to be redesigned from scratch. For a first-year unit, it was important to balance the new knowledge, competencies, and skills that students would be learning and assessing their ability to apply knowledge, competency, and skill in their project work, which would adequately prepare them for development and integration of first year content in the second year of study. It was important that each student is assessed individually on these competencies, to ensure a successful progression into the second year. A Problem-Based Learning approach, rather than project-based learning, was considered as an effective means of delivering new, ambitious content to an entire school of first-year engineering students to give them a wider appreciation and scope of engineering, as well are harmonizing the two components of the unit into a consolidated project. During Problem-Based Learning students learn about a subject through the solving of problems which do not have a single correct answer, usually working in groups. This approach 'empowers learners to conduct research, integrate theory and practice, and apply knowledge and skills to develop a viable solution to a defined problem,'[1]. In project-based learning students learn by investigating more complex problems or challenges. This approach promotes active learning, engages students, and allows for higher order thinking through the exploration of real-world problems [1]. The main difference between Problem-Based and Project-Based Learning is the outcome. The focus of Project-Based Learning is the development of an artefact or system in response to a complex and illdefined problem, in contrast to Problem-Based Learning where the outcome is simply a solution to a clearly defined problem. Problem-Based Learning could be considered a subset of Project-Based Learning in that the problem at hand is simple enough not to require a project to solve it. Project-Based Learning is often multidisciplinary, over longer timescales, and involves undertaking authentic tasks to solve real-world problems, whereas Problem-Based Learning is more likely to focus on a single topic over shorter timescales and may rely on less realistic scenarios. There is an argument that ProblemBased Learning is more reliant on group work and Project-Based Learning is more appropriate for individual self-direction. However, on this basis, what Problem-Based Learning allows students to achieve is the acquisition of knowledge rather than just the application. It also fits within project activities with a degree of complication and systems thinking, such as computing, hydraulic or water engineering related to Civil Engineering or Mechatronics projects in Australian institutions [2]. However, these case studies were delivered at more senior levels (second, third and fourth) year in the halcyon days of in-class teaching (pre-2020). The risk of adapting Problem-Based Learning in this context is that it will be delivered to an inexperienced first-year cohort getting to grips with blended learning for the first time. Problem-Based Learning has also been explored in the teaching of sustainable development to promote education innovation in student-centred learning [3]. However, this was explored as broad, complex themes which would integrate into a hybrid problem and project-based model and delivered at too high a level for first year students. However, the approach explored four learning principles that were desirable outcomes for the new unit [4]. These were:

-Constructive learning: where students learn by constructing their knowledge base, connecting new information with existing knowledge (e.g., through discussion)

-Collaborative learning: where students learn collaborating with each other to maximise their learning through peer-to-peer teaching (e.g., in small group work)

-Contextual learning: where students learn to consider relevant context of a cases in order to transfer and apply insight and knowledge to different cases (e.g., through real-world/authentic problems)

-Self-directed learning: where students learn to regulate their learning by playing an active role in planning, monitoring, and evaluating their learning process (e.g., through self-interest and formative exercises) 
These four principles would come to define the overall strategy and goals for the Design \& Computing unit; however, it still needed a framework. The Aalborg Problem Based Learning (PBL) model [5] is well-established and lends itself well to integrating knowledge and practical based elements into project work. Aalborg's unique project-organised problem-solving approach allows students to work collectively on a common project, whilst enabling individual assessment of skills and competencies. Instead of literature, lectures, and experiments; the inputs to the problem-solving activity would be competencies linked to the student's ability to design, draw, model in CAD and use programming software. See Fig 1.

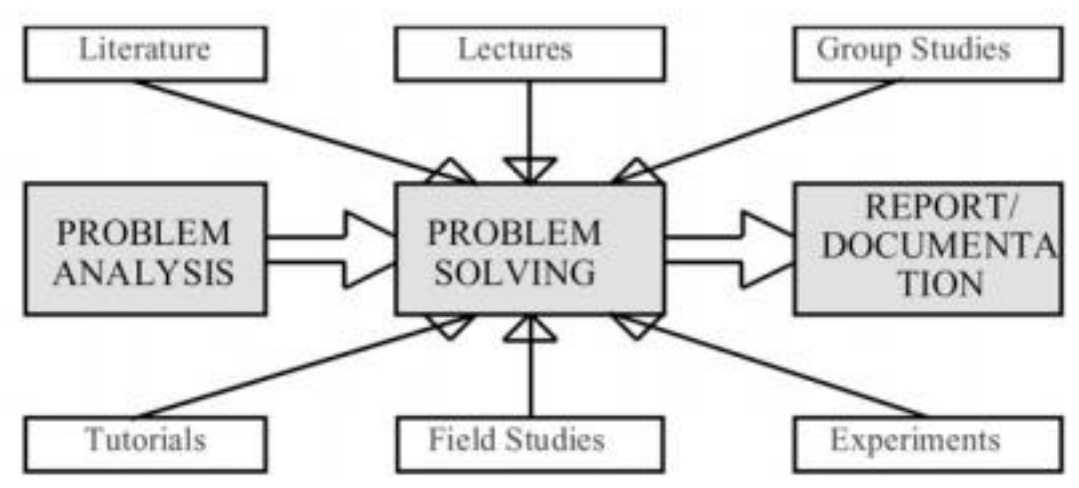

Figure 1. Principles of project-organised problem solving [5]

The Design \& Computing unit contained technical drawing, CAD, and programming elements that students required competency in before applying this in their project work. These elements would normally be traditionally taught through lectures and studio-based teaching or computing labs. However, due to the constraints of teaching spaces and limitations of live synchronous sessions, it was deemed that the project elements were of the most priority for face-to-face classes, therefore all drawing, CAD and programming activities were delivered online. These practical elements were formatively assessed to allow students to obtain feedback throughout the unit. It also offered some contingency in the new delivery of the unit that was affected by external factors, such as students not having the right equipment or internet issues. Another important element was to allow students to obtain formative feedback on their report/documentation halfway through the unit. Not only was this an important stage gate to monitor and check on student progress, but also help regulate their learning. A major theme in the unit is design, and students were asked to undertake a 5-week group project in collaboration with Engineers without Borders. The Engineering for People Design Challenge provided an opportunity for students to work together to solve a global design problem, learning core design skills and tools through collective learning. The intention of this project was not only to allow students to meet and work with new course mates, but to introduce design in a fun yet challenging project.. The adapted PBL model-which shows the structure and approach for the unit, combining practical elements as well as design and systematic thinking-is shown in Fig 2.

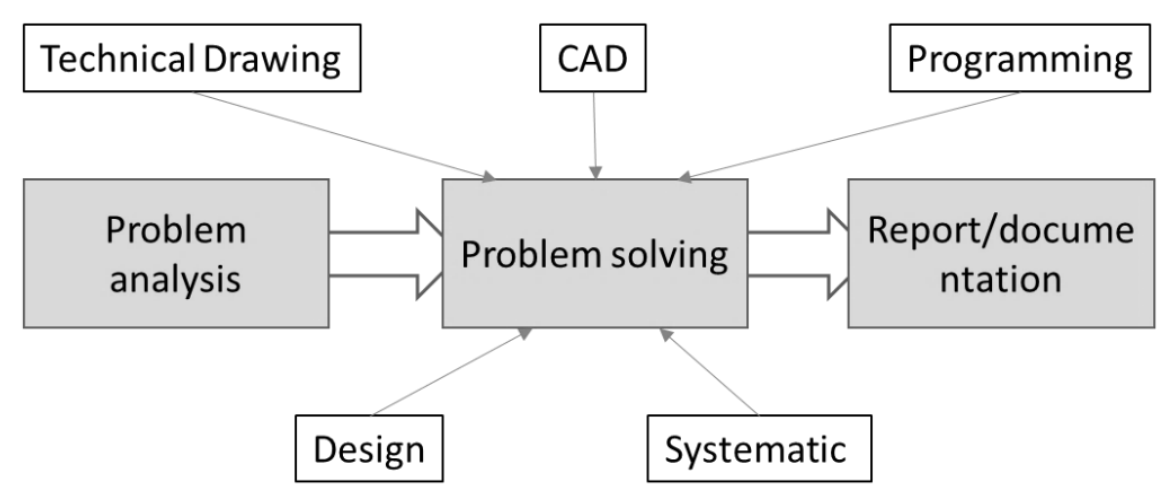

Figure 2. An adapted PBL model and framework for the unit 


\section{MULTI-DISCIPLINARY PROJECT THEME \& PROBLEM}

With the unit now containing a mix of engineering disciplines, the project theme had to be sufficiently broad but with some disciplinary nuances to help students transition well into their second year. Given a major learning outcome was to demonstrate an appreciation of the environmental, economic, social, professional, and interdisciplinary contexts, as well as understand the purpose of engineering in delivering sustainable development; a wind turbine farm context was devised. Each student, depending on their discipline, focused on a sub-system aligned with their discipline. The problem-solving aspects of the project took on two major themes, firstly it was important for students to understand the complexities of sustainable development and secondly to start appreciating systems engineering/integrated approaches as part of foundational design competencies [6]. A fictional Scottish island and context was devised based on the controversial Viking Wind Farm development on the Shetland Islands. Not only did this give the project authenticity and relevance but was also a project context that many UK-based students could connect with. To adhere to the problem-based nature of the exercise, students were presented with a collection of data, which included information on the islands, costs and detailed proposals and technical annexes They were also presented with weather and geographic data of the island, as well as a set of equations to work from. This was not presented in a sequential order, nor was there a step-by-step instruction list of how to tackle each stage of the problem. The only way students could successfully progress with the project was to make the most of in-class discussion and learn from their peers. Project phases were communicated to students using a broad design process; an adapted V-model [7] was developed to help students understand the project phases.

\section{HYBRID ONLINE \& STUDIO-BASED DELIVERY}

The design studio had to conform to Covid-19 restrictions, which included vastly reduced capacity in a session (approximately 90 students) as well as safe spacing between desks and seats; in addition, all students and staff had to wear personal protective equipment. To work around the capacity restrictions, the cohort was broken up into multi-disciplinary teaching groups of approximately 30 students: with three groups working in the studio space during a single session. Each teaching group room had dedicated audio-visual (AV) equipment with teaching assistants to provide support. A minority of students were unable to attend classes in person, for example those who were unable to travel to the UK or were required to shield or self-isolate. Rather than create a separate online session, it was deemed more inclusive to run both in-person and online classes in parallel. The intention was to allow all students to feel part of the class; and get a better appreciation of activities and interactions happening in the rooms. The online collaboration room was accessible by all students in their respective teaching groupand a live feed was visible on the projector screen in each section of the studio. Teaching assistants could interact with both students in class and in the online room simultaneously. See Fig 3.

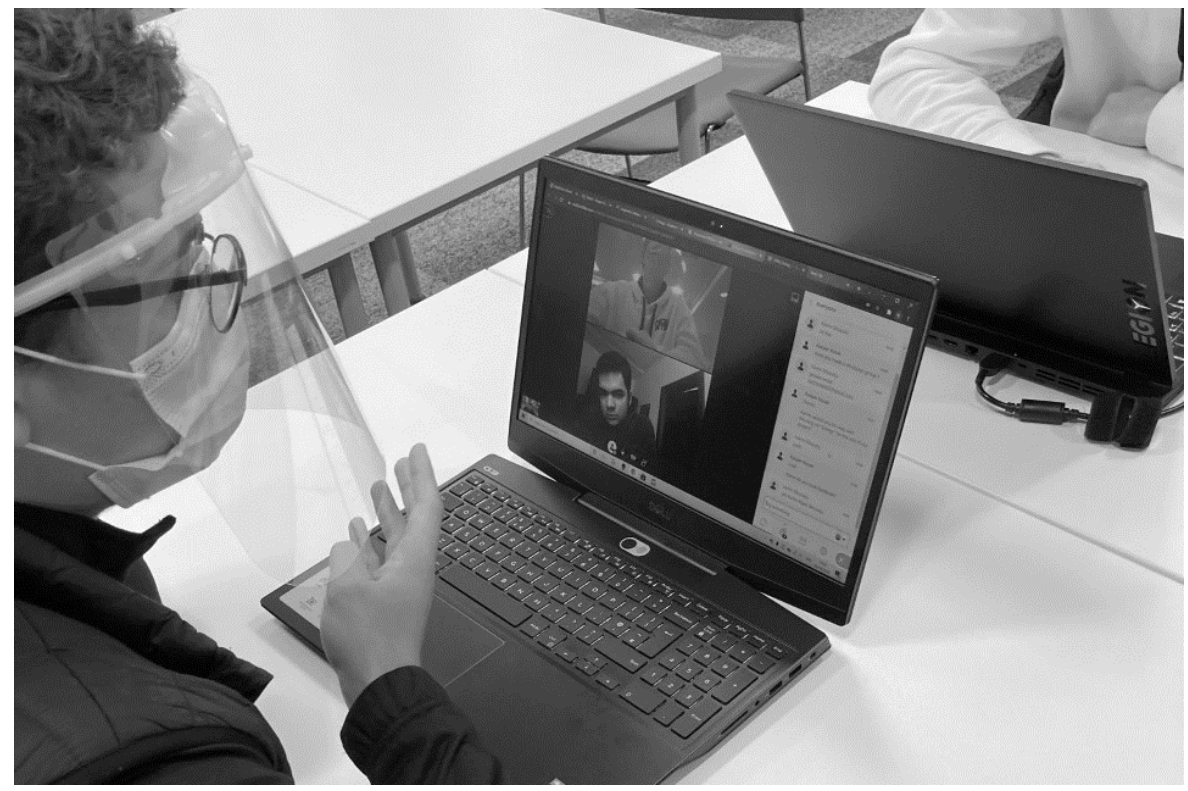

Figure 3. A design project team working collaboratively online and in-class 
This hybrid method of delivery proved highly effective for the Engineers without Borders activity in which the larger teaching group was broken down into smaller groups of 4 students. Each group had their own online group space in which to collaborate, share files and complete a collaborative learning journal week-by-week to reflect on their understanding of the design process as an essential part of the PBL process. [8]. This delivery method was intended to be supplementary to on-campus teaching, with a contingency in place to run the class entirely online if required.

\section{BEST LAID PLANS}

The first five weeks of the unit were intended to be a great opportunity for students to socialize and work on an introductory design project, but with a spike in Covid-19 infections and students self-isolating, more and more students became reliant on accessing their learning through online collaboration rather than attending class in person. Class sizes dwindled until the fifth week, when groups were to present their work in class. The AV system in each class could allow students to able to present their work in class with some of their team members online; some groups presented their work entirely online-with students in and out of class sharing the same collective experience. Over time students who were selfisolating returned to class; but the onset of a second national lockdown made students return to their home domicile for the remainder of term. The engineering drawing content in the first few weeks of term proved particularly difficult to deliver online, not only as some students had not received their equipment in time for the start of class but also due to the constraints of online delivery. It was difficult for teachers and students to show their work onscreen and only a small minority of teachers had access to a visualizer. The start of the individual project required some reinforcement, as it was not clear to some students that the tools and techniques, they had learned in both their drawing practical and group design activities were meant to be directly applied in their project work. This highlights the key differences between Problem-Based Learning and traditional project-based learning. Many students demanded clearer instructions and wanted to be told exactly what to do from teachers, rather than discuss activities and learn, on a collective level, from their peers. The last two weeks of the term had to be delivered online as remaining students on campus returned to their homes before the Christmas break. The online delivery of CAD was somewhat more successful than drawing, as teachers and students had the ability to easily share their screens. Teachers could also take control of student's computers to access tools and features as also observed in the programming delivery in the second term. At the start of second term, and with the UK under another national lockdown, all classes had to be delivered online. This shift of in-class PBL delivery to online proved difficult. Each class had to be far more structured to promote discussion and it was difficult for students to interact in small groups. It was clear from student feedback that students did not enjoy the use of breakout rooms for online group discussions.

\section{DIscussion}

It is difficult to determine whether Problem-Based Learning was too much of a challenge for a first-year cohort under unprecedented circumstances. For Aalborg, the PBL approach is implemented throughout every year of study, albeit in a group context. Rather than individual projects, where students would have more reluctance to discuss and share their work with peers it is more likely a small group project, for example a team of 3 students in each discipline working on their own sub-system, would have been more appropriate-and more in line with the project-oriented approach. This is more difficult to achieve in practice, as there are not an equal number of students within each discipline to create balanced teaman alternative could have been to keep students in their small groups from the Engineers without Borders exercise. Had the unit been delivered asynchronously, there is a risk that students may have worked in isolation with limited class engagement or collaboration and the four learning principles as a strategy of the unit would remain unfulfilled. This may be an issue with aspects of hyflex teaching methods [9] which allow students to engage with content in an asynchronous online capacity-and thus does not facilitate collaborative learning in the same way. It was observed that some students who approached the project in this individualistic way made little progress, failed to attend class, or engage with formative exercises. They soon got very lost in what was going on and where they needed to be in the project. It was also evident that a significant number of students struggled, not only with the unit content but also external factors, but they struggled together. It is also evident that sketching and engineering drawing would have been more effective if delivered in class, as the introductory group design task could have been delivered completely online and achieved most of the same outcomes. It is another good example that some topics can be very difficult, if not impossible, to deliver effectively online, and 
with drawing requiring the most physical interaction and observation, it should have taken priority for in-class teaching in the first 5 weeks. CAD and programming, being in the digital domain and operated solely via computers, naturally lend themselves to online delivery. The hybrid approach to online and in-class teaching proved to be successful-and has been noted in literature as a way of working in virtual teams with other universities [10]. In the context of this unit, it was a vital tool for students who were not on campus to engage in collaborative learning with their peers on campus-and be part of the collective learning experience.

\section{CONCLUSION AND RECOMMENDATIONS}

Delivering design and computing competencies via Problem-Based Learning may have been too high an expectation to be understood by all first-year engineering students, and it may be that a hybrid model of project and Problem-Based Learning may be more suitable to different learning styles-and offer a little more structure to students who need more instruction and self-direction. Two project contexts may also work-allowing students to experience both learning formats (e.g., a typical engineering product design project) rather than define the overall structure of a module or unit. Another outcome is not to see online and in-class teaching as two separate entities, and that a hybrid approach may be a vital component in making PBL a success in a blended learning environment that requires a high level of adaptability, such as collaborations between Universities or distance-learning modules. The student feedback from the unit was polarized, for some students it "was the only unit to offer a form of socializing, created an environment to develop project skills and technical analysis" and "gain valuable learning experience by collaborating with others..." Some students were also able to appreciate the context and scope of the unit, appreciating that "the skills which are taught in these units are really intellectually stimulating and crucial for anyone wanting to pursue a career in engineering" and understand the "steps needed to create, design and test a system but in an educative way. Instead of just teaching us the steps, we got to apply the knowledge we were learning to a project". However, it was clear that some students did not adapt well to this delivery model and needed to "make it more clear what needs to be done" with "clearer and set instructions" Whilst not suited to everyone, for some "one good thing about this project is that it shows student [s] the steps needed to create, design and test a system but in an educative way. Instead of just teaching us the steps, we got to apply the knowledge we were learning to a project. Also, during the year, this project showed me how to go search, by myself, information needed for my project"

\section{REFERENCES}

[1] Savery, J. R. Overview of problem-based learning: Definitions and distinctions. 2006. Interdisciplinary Journal of Problem-based Learning, 1(1)

[2] J.E.Mills and D.F. Treagust Engineering education - is problem-based or project-based learning the answer? 2003. Australasian journal of Engineering Education

[3] R. Cörvers et al. Problem-Based and Project-Based Learning for Sustainable Development 2016. Sustainability Science pp 349-358, Springer.

[4] D. Dolmans, H. Schmidt The problem-based learning process. 2010 In: Van Berkel H, Scherpbier A, Hillen H, van der Vleuten C (eds) Lessons from problem-based learning. Oxford University Press, Oxford

[5] A. Kolmos, F. K. Fink and L. Krogh. The Aalborg PBL model - Progress, Diversity and Challenges, 2006, p13 (Aalborg University Press)

[6] The Accreditation of Higher Education Programmes (AHEP) 2020 p34. AHEP-4 ${ }^{\text {th }}$ Edition

[7] Systems Engineering Fundamentals 2001. Defense Acquisition University Press

[8] T.Morgan Exploring socially shared regulated learning in PBL using group digital learning diaries: A study design 2020. Proceedings of the 22nd International Conference on Engineering and Product Design Education (E\&PDE 2020), VIA Design, VIA University in Herning, Denmark. 10th-11th September 2020

[9] M.Mahoney Roundtable Report: Making Hyflex Teaching Work on Your Campus, 2021, The Chronicle of Higher Education

[10] A. Wiek, et al A global classroom for international sustainability education. 2013 Creat Educ $4(4 \mathrm{~A}): 19-28$ 